\title{
Thermal comfort and personal protective equipment (PPE)
}

\author{
Ronaldo André Castelo dos S. de Almeida ${ }^{\mathrm{a}}$, Marcelo Motta Veiga ${ }^{\mathrm{b}^{*}}$, Francisco José de Castro Moura \\ Duarte $^{\mathrm{c}}$, Luiz Antônio Meirelles ${ }^{\mathrm{c}}$ and Lilian Bechara Elabras Veiga ${ }^{\mathrm{c}}$ \\ ${ }^{a}$ Environmental Health Department, National School of Public Health, Oswaldo Cruz Foundation, Ministry of \\ Health, Rua Leopoldo Bulhões, 1480 / 503 - Manguinhos, 21.041-210 - Rio de Janeiro - RJ - BRASIL \\ ${ }^{b}$ Strategic Management Department, Business School, Federal University of Rio de Janeiro State, Rua \\ Voluntários da Pátria, 107, Botafogo, Rio de Janeiro, Brazil, 22.270-010 \\ ${ }^{c}$ Alberto Luiz Coimbra Graduate and Research in Engineering Institute - (COPPE), Federal University of Rio de \\ Janeiro, Av. Horácio Macedo, 2030, Prédio do Centro de Tecnologia, Cidade Universitária, 21.941-914
}

\begin{abstract}
Personal Protective Equipment (PPE) is considered the last preferred solution to an Occupational Safety Health $(\mathrm{OSH})$ system. Brazilian OSH legislation assumes and requires PPE usage to neutralize the possibility of pesticide contamination. This study examines the inadequacy of the PPE used in a tomato crop, particularly from the standpoint of thermal comfort. This study made observations regarding heart rate and body temperature in a controlled environment using a treadmill (with and without PPE) of 12 volunteers; and during the process of rural labor (at rest and in normal work routine) of 2 actual rural workers. Comparing the results of the treadmill test (with and without PPE) which tried to reproduce the same level of effort and environmental conditions of the actual rural work, this study demonstrated that PPE makes thermoregulation harder and tympanic temperature reaches higher values with the same level of effort. Moreover, body temperature increases quickly: with PPE it took 15 minutes to raise $1^{\circ} \mathrm{C}$ in body temperature, compared to 40 minutes without PPE. The results of this study indicated that the use inadequate PPE might pose thermoregulation risk to rural workers.
\end{abstract}

Keywords: Pesticide, Personal Protective Equipment, Agriculture, Contamination, Thermal Comfort.

\footnotetext{
* Corresponding author: mveiga@ensp.fiocruz.br
} 


\section{Introduction}

The use of PPE (Personal Protective Equipment), although the last preferred solution, must be considered within an integrated and systematic vision of occupational problems. For this reason, the efficiency of the entire occupational health and safety system is intimately related to the way a balanced choice of alternatives for prevention, protection and control is made [1].

Various problems can cause PPE to be inadequate for certain working conditions. Some desirable characteristics that were designed to provide greater occupational health and safety may also introduce operational difficulties in many work situations. For example, protective clothing that is more resistant to permeability can also be uncomfortable because it is too heavy and/or too hot to wear given the local climate. There is also the problem of adequacy of PPE to anthropometric characteristics.

In Brazil this problem of the inadequacy of PPE to ergonomic and environmental conditions is particularly present in agriculture, especially in small rural communities, where commonly farmworkers do not wear obligatory PPE while handling and applying agricultural chemicals (see Figure 1). One of main reasons is that many PPE items cause thermal discomfort, which in extreme cases can even lead to heat stress [2].

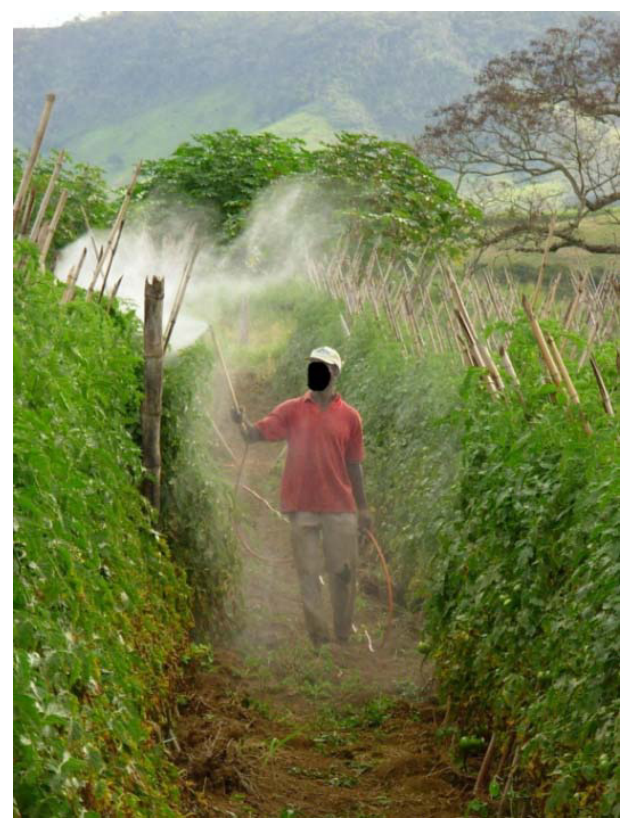

Fig. 1 - Brazilian Rural Worker not using PPE
The use of PPE is one of the alternatives used to protect the worker, having as consequence the adverse effect on body's temperature balance, since it may impede the heat loss to the environment in a satisfactory manner $[3,4]$.

The immediate consequence is the increase in body temperature. The thermal comfort is a relevant issue for occupational safety and health. Some studies assessed the effects of temperature on human body $[5,6]$.

This study examines the inadequacy of the PPE used in a tomato crop, particularly from the standpoint of thermal comfort. This study addressed this subject from different perspectives: from the physiological and clinical viewpoint to the sanitary and legal aspects.

\section{Thermal Confort}

The thermal physiology of the human body is complex, but can be said to function as a thermodynamic system that regulates heat, trying to maintain internal body temperature near $37^{\circ} \mathrm{C}$. Thermal comfort, then, is associated with the difficulty of losing or retaining heat to maintain proper body temperature [7] .

However, although necessary for many work activities, the use of personal protection items can interfere in this thermal balance by hindering the loss of excess heat by the human body by convection, radiation and evaporation. Heat is retained any time the human body cannot manage to lose enough heat because of the thermal isolation caused by the use of PPE, resulting in a consequent increase in body temperature [5].

Temperature affects professional performance, and body temperatures above optimal limits affect physical and mental performance. If these limits are exceeded it can provoke physiological and pathological problems. In short, when the human body overheats, worker productivity declines $[8,9]$.

However, the limits established in legislation for thermal comfort and temperature extremes are based on acute reactions of workers exposed to heat, not on chronic effects. For this reason, it can be said that the literature on continued and prolonged exposure of workers to heat still leaves much to be desired [6].

Another aggravating factor for the use of PPE by rural workers in countries with hot and humid climates is the fact that working under such conditions is more unhealthful than carrying out the same activi- 
ties in more amenable conditions. A worker carrying out a moderate activity under amenable conditions, using light clothing, takes an average of 90 minutes to gain $1.5^{\circ} \mathrm{C}$ of body heat. This same worker wearing impermeable clothing made of synthetic material takes only 20 minutes to gain the same heat. There-

\section{The Use of PPE in Tomato Crops}

A survey conducted by the Brazilian Institute of Geography and Statistics (IBGE) among tomato growers in a small rural community in the state of Rio de Janeiro in 1990 found that the majority of farmworkers $(70 \%)$ did not customarily use any personal protection equipment when preparing and applying agricultural chemicals [2].

Preliminary results of another study conducted recently among workers in this same region ratify the earlier findings of the IBGE. This new study found that the majority of the workers are young (20 to 25 years old) with little schooling (1 to 3 years of formal education). It was also observed that the farmworkers did not follow the recommendations on maintenance, washing, dressing/undressing, disposal and storage of protective gear. The main complaint about using PPE was thermal discomfort, particularly on hot days. Another common complaint was the difficulty of breathing caused by the face mask worn while applying agricultural chemicals.

The basic components agricultural PPE (see Figure 2) is: Rubber boots, impermeable pants, plastic face mask, long sleeve shirt, plastic apron, impermeable face and neck cover; and rubber gloves.

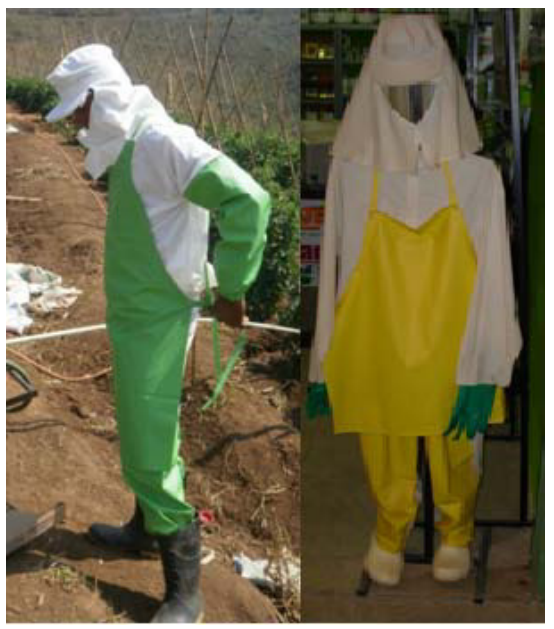

Fig. 2 - Basic Agricultural PPE fore, the type of protective clothing, associated with environmental conditions, influences how long a worker can be exposed to these conditions within the range of thermal comfort [10].

The region studied has a cool and dry winter and hot rainy summer. The average annual temperature is between 18 and $22^{\circ} \mathrm{C}$. However, at the extremes the temperature can exceed $40^{\circ} \mathrm{C}$ in the summer and fall close to $0^{\circ} \mathrm{C}$ at the highest altitudes in the winter.

The protective clothing and gear, designed to minimize contamination by agricultural chemicals, also reduce air circulation within, causing a veritable stifling effect. Brazilian farmworkers often work over 12 hours a day, six days a week, at outside temperatures that can reach $40^{\circ} \mathrm{C}$ with high humidity in the summertime, making for very insalubrious working conditions that be detrimental to health.

Considering the estimates presented above that it takes 20 minutes with PPE and 90 minutes with normal clothing for the body temperature of a worker engaged in moderate activity to increase by $1.5^{\circ} \mathrm{C}$, the conditions of heat and humidity faced by Brazilian agricultural workers in reality means that using PPE as recommended can cause intolerable body heat.

This makes the resistance of farmworkers to the use of certain protective items understandable. For them the tradeoff is between the certain and acute short-term thermal discomfort of wearing PPE and the risk of contamination, which in the majority of cases brings uncertain, chronic and long-term consequences, ones that are asymptomatic and hard to diagnose [4] .

\section{Results and Discussion}

Thermal comfort is a relevant issue for occupational safety and health. This study examines the inadequacy of the PPE used in a tomato crop, particularly from the standpoint of thermal comfort.

In order to assess thermal comfort and PPE inadequacy, this study made observations regarding heart rate and body temperature in a controlled environment using a treadmill (with and without PPE) of 12 volunteers; and during the process of rural labor (at rest and in normal work routine) of 2 actual rural workers. 
The assessment of the workers condition, with and without PPE, was performed using a treadmill in order to simulate the real work conditions. In each working stage, a survey was applied, regarding the thermal sensation proposed by ISO 10551/95 in order to supplement monitoring, which enabled comparing selected method to a validated method.

Among many measuring methods of body temperature, this study selected tympanic temperature, as it method enables quick and precise measurements. Although the tympanic evaluation is not the most accurate method, it was considered the most suitable due to the particular conditions of this study [4].

In addition, there are some obstructions, such as the presence of a sweat layer on the inner ear that influences temperature measurement, as sweat temperature is probably smaller than tympanic temperature.

Tomato crops lengthen from 4 to 5 months, beginning with soil preparation and ending with harvest. The observation, data collection and monitoring were conducted during an entire crop extent, covering all its phases.

The stage of greatest risk to worker health starts after the plants attain a height of approximately 90 $\mathrm{cm}$. From this point, the need for pesticide applications is higher due to greater susceptibility to pests and crop diseases. The plants size increases the time taken to spray pesticides, resulting in a greater worker exposure.

The experiment with the 2 rural workers was performed during 3 normal days of pesticide spray in different crop phases. The extent of the pesticides spray varied from 40 to 65 minutes. The time-span to increase $1 \mathrm{oC}$ in the workers' body temperature was around 15 minutes. Environmental temperature varied from 26 to $29 \mathrm{oC}$.

The questionnaire proposed by ISO $10551 / 95$ was used to evaluate thermal comfort. Furthermore, it was assigned a numerical value to each possible answer to subsequently use the data to test for correlation with the values obtained by measuring the tympanic temperature.

Correlation was performed in data obtained, with the support of statistical software R. The test was done between the tympanic temperature values in first, second and third days of data collection and the values assigned in questionnaire (ISO 10551/95).

Thus, the tests indicated high correlation between tympanic temperature and the thermal sensation perception of rural workers. This result confirmed the possibility of using the tympanic measure to check the level of thermal stress during a workday.

Comparing the results of the treadmill test (with and without PPE) which tried to reproduce the same level of effort and environmental conditions of the actual rural work, this study demonstrated that PPE makes thermoregulation harder and tympanic temperature reaches higher values with the same level of effort. Moreover, body temperature increases quickly: with PPE it took 15 minutes to raise $1{ }^{\circ} \mathrm{C}$ in body temperature, compared to 40 minutes without PPE.

Core body temperature tends to increase with high temperatures. This increase in body temperature can be higher than tympanic thermometer reflects. Considering the possibility that tympanic measures underestimate body temperature in values over $37.5^{\circ} \mathrm{C}$, other vital signs should be considered harmful to human body, e.g. excessive thirst, moodiness, dizziness, and restlessness during work. The results of this study indicated that the use inadequate PPE might pose thermoregulation risk to rural workers.

\section{References}

[1] International Labour Office (ILO) Guidelines on occupational safety and health management systems, ILO-OSH 2001, Geneva. 2001

[2] Coutinho, J.A.G.; Freitas, E.A.V.; Ferry, R.V.; Lins, L.C.G.; Santos, J.A. Dos; Cavalcante, N.S.D.; Whately, M.H. E Maticato, A.T. Uso de Agrotóxicos no Município de Pati do Alferes: Um Estudo de Caso. Caderno de Geociências, IBGE, n. 10. pp. 23-31, 1994.

[3] Veiga, M. M.; Duarte, F. J. C. M.; Meirelles, L. A.; Garrigou, A.; Baldi, I., A contaminação por agrotóxicos e os equipamentos de proteção individual (EPIs). Revista Brasileira de Saúde ocup A acional, v.32(116), p.57-68, 2007.

[4] Almeida, R. A. C. S; Veiga, M.M. Processo de Trabalho Rural e EPIs: Discussão Sobre Termorregulação Corporal. Revista P\&D em Engenharia de Produção V. 08 N. 02 (2010) p.29-39

[5] Crockford, C. W. Protective Clothing and Heat Stress: Introduction. Annals of Occupational Hygiene. V. 43, n. 5. p. 287-288, 1999.

[6] Wood, L. Heat Resistant. Occupational Health. v.56, n.7, p.25-29, 2004.

[7] Fundacentro. Avaliação de Conforto Térmico - Contribuição à aplicação prática das normas internacionais. Álvaro César Ruas. 2001.

[8] Ahasan, Rabiul; Mohiuddin, Golam; E Faruquee, Syed Mohammed. Strenuous Tasks in a Hot Climate - A Case Study. Work Study. 51, 4/5. 2002. pp. 175-181.

[9] Rodahl, K.. Occupational Health Conditions in Extreme Environments. Annals of Occupational Hygiene. V. 47, n. 3. p. 241-252, 2003

[10] Havenith, George. Heat Balance When Wearing Protective Clothing. Annals of Occupational Hygiene. V. 43, n. 5, p. 289-296, 1999. 